\title{
Segundo Congreso Chileno de Ciencias Forestales
}

En el Campus Isla Teja de la Universidad Austral de Chile, en la ciudad de Valdivia, durante los días 10 al 12 de noviembre de 2004, se realizó el "Segundo Congreso Chileno de Ciencias Forestales". Este evento lo organizó la Facultad de Ciencias Forestales de la UACh, adhiriendo al cincuentenario de la fundación de la Universidad y de la propia Facultad de Ciencias Forestales.

Con el patrocinio de la Sociedad Chilena de Ciencias Forestales, Corporación de Derecho Privado con personería jurídica, que se fundó hace algunos años por las principales instituciones de investigación y enseñanza forestal del país, y cuya misión es fomentar el progreso de las ciencias y técnicas forestales y su difusión mediante reuniones, publicaciones y eventos masivos que reúnan a especialistas, científicos y profesionales del sector, la Facultad de Ciencias Forestales de la UACh, una de las fundadoras de la Sociedad homónima, aceptó el compromiso de organizar y realizar la segunda versión de un Congreso Forestal, que por estatutos debe realizarse cada dos años.

La oportunidad para esta reunión bianual coincidió con una fecha trascendente para la UACh y su Facultad de Ciencias Forestales: celebrar 50 años de exitosa actividad académica, investigativa y apoyo al desarrollo forestal regional y nacional. Durante estos 50 años de existencia, la Facultad de Ciencias Forestales-UACh ha impartido enseñanza de pre y postgrado al mejor nivel de excelencia, y paralelamente llevado a cabo una importante y variada labor de investigación y extensión, que se han canalizado en diversas publicaciones seriadas, esporádicas y libros. Entre estas publicaciones indexadas destaca esta revista $B O S Q U E$, la más antigua y continuada publicación científica forestal del país.

El creciente interés por publicar en BOSQUE los resultados de proyectos, investigaciones y opiniones técnicas no sólo del país, sino que también y en forma creciente, desde el extranjero, animó al Comité Editor de la Revista a dedicar su primer número del año 2005 para incluir aquellos trabajos, que, a juicio de los editores, mejor representan la diversidad temática y calidad técnica de los trabajos expuestos en el Segundo Congreso Chileno de Ciencias Forestales efectuado en Valdivia el año pasado.
El actual número 26(1) de BOSQUE contiene cuatro trabajos por cada área de especialidad de la Facultad, esto es, SILVICULTURA, MANEJO y TECNOLOGÍA, que se han estructurado al formato y extensión de la Revista, debido a que la mayor parte de los trabajos originales fueron entregados in extenso, en un CD incorporado al texto Resúmenes y Actas, que recibió cada persona inscrita en el Congreso. En total, se expusieron en forma simultánea en cuatro salas, 120 trabajos, siete de ellos en forma de Invitados Especiales, y 27 pósters en paneles adhoc. Concurrieron investigadores de 18 universidades y ocho institutos de investigación, nacionales y extranjeros, provenientes de nueve países americanos y europeos.

Esta sorprendente y muy motivadora concurrencia, en especial la foránea, indica la gran importancia que se le confiere a las reuniones científico-técnicas en materias forestales, y debiera alentar a la Sociedad Chilena de Ciencias Forestales a patrocinar eventos con un alcance mayor, esto es, a promocionar el Tercer Congreso Chileno y, al mismo tiempo, el Primer Congreso Internacional de Ciencias Forestales, toda vez que es notoria la concurrencia extranjera, como se constató en Valdivia.

Es indudable que eventos como los mencionados requieren de la dedicación y compromiso institucional, además del personal idóneo, y de recursos financieros para solventar los variados requerimientos y necesidades de diversa naturaleza que demandan la organización y realización físicosocial de ellos. Es, por lo tanto, y muy sincero por cierto, un grato deber expresar el agradecimiento a los Patrocinadores y Auspiciadores del Congreso, en especial por sus aportes materiales y financieros; a todas las personas de la Facultad que posibilitaron, con su desinteresada colaboración, la oportuna y adecuada realización del mismo, y en forma muy destacada a TODOS y cada uno de los autores y expositores de trabajos invitados, voluntarios y pósters, quienes con su presencia y aporte le dieron el realce y connotación que tuvo el SEGUNDO CONGRESO CHILENO DE CIENCIAS FORESTALES.

Prof. Dr. Rubén Peñaloza W. Coordinador General del Congreso 